\title{
A prática da "bocha" na SOERAL: entre o jogo e o esporte
}

Marco Paulo Stigger Raquel da Silveira

Resumo: Neste trabalho, procuramos, a partir da etnografia, compreender aspectos do modo com que os sócios da Sociedade Esportiva Recanto da Alegria/ SOERAL vivenciam seu tempo livre. Centrando a atenção na prática o jogo da bocha que lá acontece, perguntamos se esta atividade se insere no contexto do jogo ou do esporte. Sem, efetivamente, tentar responder a esta pergunta, fizemos uso daquela realidade empírica para problematizá-la e provocar a discussão acerca das relações entre jogo e esporte. Esta aproximação nos mostrou as dificuldades que encontram os que analisam o esporte e o jogo numa perspectiva dicotômica, distanciada dos contextos empíricos onde elas se realizam.

Palavras-chave: Lazer, Jogo, Esporte, Etnografia.

Não é difícil identificar, na bibliografia disponível nas ciências sociais, que a área do lazer é relativamente negligenciada, se comparada aos estudos onde o trabalho é a categoria central. Apesar disto já ter sido constatado por vários autores (Elias e Dunning, 1992; Fortuna, 1995; Magnani, 1984), e que, em certa medida, este fato ainda seja possível de ser confirmado na realidade atual, nos dias de hoje já é possível encontrar uma produção acadêmica razoável sobre a temática. Ao que parece, os autores que hoje vêm se interessando pelo lazer enquanto esfera importante da vida moderna, reconhecem que as práticas realizadas no tempo livre, não são a antítese da vida cotidiana, mas a sua continuação (Fortuna, 1995).

*Doutor em Ciências do Desporto. Professor Adjunto na Escola de Educação Física da Universidade Federal do Rio Grande do Sul

** Acadêmica de Educacão Física da Universidade Federal do Rio Grande do Sul, bolsista de Iniciação Científica/PROPESQ-UFRGS:

Movimento, Porto Alegre, v. 10, n. 2, p.37-53, maio/agosto de 2004 
Apesar do lazer ser considerado um tema menor, talvez ele tenha alcançado maior visibilidade e chamado a atenção dos acadêmicos, pela confrontação com uma realidade concreta atual, que põe em evidência a sua relevância, identificada, tanto no crescimento que o mercado do lazer tem experimentado, assim como pela demanda social para a qual muitos governantes têm se preocupado em dar respostas aos seus eleitores. Sobre este último aspecto, chama a atenção a presença de enormes parcelas das populações urbanas que se aglomeram nos parques e praças das cidades, em especial aos fins de semana, o que acaba por exigir respostas dos poderes instituídos.

Dentre as diversas formas de ocupação dos parques e das praças das cidades, as atividades lúdico-esportivas evidenciam-se de maneira especial. Sendo já constituintes da paisagem urbana, a sua presença não causa nenhum estranhamento ao observador. Junto com outras evidências que poderiam ser apresentadas, este fato que, acreditamos, não necessita ser documentado - reforça a idéia da indiscutível inserção destas práticas na vida moderna, e a sua capacidade de trazer, em torno de si, um universo diversificado de significações capazes de mobilizar indivíduos de todos os lugares, extratos sociais, sexos, idades e posições ideológicas.

Fazendo parte da vida da cidade, estas práticas ganham visibilidade e se desenvolvem nos espaços urbanos, onde se acumula uma multiplicidade de pessoas, que muitas vezes pouco têm em comum, além da vontade de movimentar o corpo e/ou de estar no mesmo local. Suas idéias e suas razões para estarem presentes ao mesmo tempo e no mesmo lugar são as mais diversas, mas, estando ali, participam de um tipo de sociabilidade que, indiscutivelmente, também faz parte dos seus estilos de vida. É neste sentido que um sem-número de práticas acontecem dentro de lógicas bastante diferenciadas, que estão vinculadas a protagonistas bastante diversificados, e que coexistem dentro de inúmeras formas de convivência e organização.

Neste contexto se encontram as atividades de lazer que acontecem no Parque Farroupilha, um importante espaço público de Porto Alegre. Também chamado de Parque da Redenção, é composto por diversos ambientes ${ }^{1}$, onde é realizada uma grande variedade

1 Como a cafeteria, o lago, o auditório, as quadras esportivas, a pista de atletismo, o parque infantil, as canchas de bocha, os recantos, o mini-zoo, o orquidário, o Mercado Bom Fim, entre outros.

Movimento, Porto Alegre, v. 10, n. 2, p.39-55, maio/agosto de 2004 
de atividades, tanto de caráter eventual e auto organizadas ${ }^{2}$ como aquelas que apresentam alguma formalidade, inclusive com a intervenção do poder público. ${ }^{3}$ Dentre os diversos grupos que lá convivem, chama a atenção a Sociedade Esportiva Recanto da Alegria (SOERAL), um coletivo de homens de idade avançada que freqüenta aquele local, onde - num ambiente de muitas interações - desenvolvem diversas atividades, em especial os jogos de cartas, o jogo de dominó, o jogo de damas, o jogo de xadrez e o jogo da bocha. Além da prática das atividades lúdicas específicas, seus sócios participam de uma rotina diária, que os inclui num universo cultural com o qual se identificam e que tem uma forma particular de sociabilidade que o sustenta.

Conforme informam dois de seus participantes mais antigos, isto ocorre já há 28 anos, ${ }^{4}$ quando a SOERAL foi fundada "por uma meia dúzia de abnegados na época que resolveram fundar um canto, um recanto de alegria, comunicação, para o pessoal se encontrar" (Irineu, 69 anos). Este espaço é hoje localizado em uma área demarcada, a qual não passa desapercebida para qualquer transeunte: apesar do parque ser público, os participantes da SOERAL cercaram e cobriram o "cantinho da Redenção" (Irineu) e conseguiram, junto ao poder intituído, legitimar a sua presença no local. Seu Irineu se orgulha do que a SOERAL é hoje, quando relata aspectos da trajetória do grupo:

É, eram um grupo de amigos, naépoca opessoal que estava começandoa freqüentar aqui, jogavam aquela bochinha, na época simples, como se diz (...), porque era canchinha de chão (...), o pessoal estava fazendo e ali no cantinho da Redenção, derepente opessoal foram se reunindo, seencontrando, trocandoidéia. Sonhavam com algo maior, hoje está aí a realidade, hoje deixou de ser sonho (...), hoje é uma realidade.

2 Corridas; caminhadas; passeios; encontros; piqueniques.

3 Feira Ecológica; Feira de Artesanato e Antigüidades; Brique da Redenção; Shows; Baile da Redenção.

4 Segundo relato do "seu" Irineu (um dos seus ex-presidentes), do "seu" Acemi (um dos fundadores) e do "seu" Manoel (também um dos fundadores), o grupo teve a sua fundação em 28 de dezembro de 1976.

5 Quando este informante fala em cantinho, é talvez pelo fato da SOERAL ocupar, em termos de espaço físico, uma pequena área localizada numa das extremidades do Parque, a qual é delimitada por uma area localizada tuma das extremidades do Parque, a qual é delimitada por uma cerca e, em parte, coberta por telhados. No seu interior, existem duas canchas de bocha com piso sintético (protegidas sob o telhado), uma cozinha (tipo bar), um banheiro, e várias mesas destinadas aos jogos de cartas, dominó, damas e xadrez (parte destas mesas também estão cobertas por um telhado).

Movimento, Porto Alegre, v. 10, n. 2, p.39-55, maio/agosto de 2004 
Contando, com em torno de 300 sócios efetivos, ${ }^{6}$ a SOERAL mantém, sistematicamente, uma grande freqüência de participantes, em especial no Sábado, no turno da tarde. ${ }^{7}$ Com um perfil bastante heterogêneo, em seu interior são encontrados senhores, em sua grande maioria aposentados, que possuem origens profissionais distintas, sendo médicos, ex-militares, trabalhadores rurais e comerciários algumas das possibilidades encontradas. Não possuindo origens sociais comuns, fazem da SOERAL um espaço de contato particular, onde o lúdico constitui-se o principal condutor do seu convívio. Destes - e mesmo que também pratiquem as outras atividades - grande parte se vincula fortemente ao jogo da bocha, um jogo praticado tradicionalmente, em todo o Rio Grande do Sul.

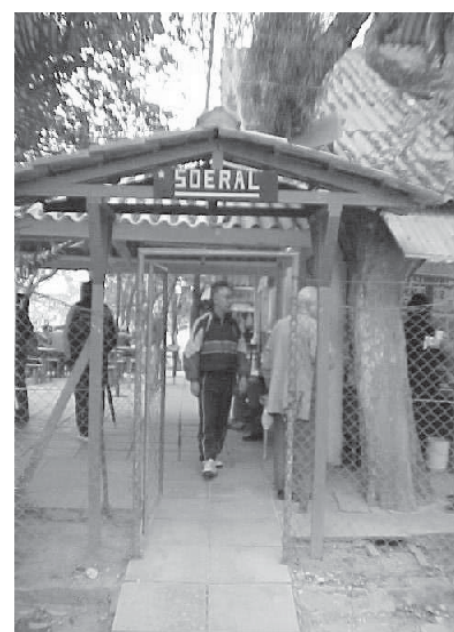

Figura 1. Portão de entrada da SOERAL

6 São considerados sócios todos aqueles participantes que, tendo mais de 40 anos de idade, estiverem cadastrados e passarem a pagar a mensalidade de $\mathrm{R} \$ 4,00$. Isto lhes dá o direito de usar as instalações do local e participar das eleições anuais, tanto para o Conselho Deliberativo, quanto para a Diretoria do grupo. Além disto, ser sócio é uma condição para fazer parte das equipes representativas do grupo. Apesar de, na sua maioria, seus freqüentadores serem homens de idade avançada (mais de 50 anos e, principalmente, aposentados), não é raro serem encontrados, no local - e ainda que não sócios -, alguns jovens praticando as mesmas atividades dos demais (isto foi identificado, em especial, entre os jogadores de xadrez).

7 Durante toda a semana (manhã e tarde), há a presença de pessoas (sócios e/ou não sócios) no local, participando das diversas atividades, sendo o Domingo o dia de menor frequêencia e o Sábado o de maior movimentação no local. Para que se possa ter uma idéia do envolvimento dos participantes da SOERAL, vale citar alguns dados obtidos no diário de campo realizado no Sábado 19/07/2003,

Movimento, Porto Alegre, v. 10, n. 2, p.39-55, maio/agosto de 2004 
Particularizando a análise no jogo da bocha que ocorre no contexto da SOERAL, busca-se saber como a participação neste grupo - e, em especial a prática deste jogo - se inserem no modo de vida dos seus protagonistas. Quais são as características desta atividade e como ela pode ser relacionada com as características de outras, no campo das práticas esportivas? Que significados são atribuídos ao jogo da bocha pelos seus praticantes e como eles se relacionam com os de outras atividades no campo dos esportes? Que fatores - vinculados a estes significados - são evidenciados na dinâmica do grupo? Como estes fatores se relacionam com a participação de cada indivíduo no contexto do seu grupo de convivência?

Estas são algumas das perguntas que procuraremos responder, buscando, além de elementos que ajudem a compreender a dinâmica do grupo em torno do jogo da bocha, proporcionar reflexões que se inserem no campo da Sociologia do Esporte. De forma especial, procuraremos nos aproximar daquelas discussões que se referem às fronteiras entre esporte e jogo, algo pouco debatido neste contexto, mas que - exatamente por isto - talvez mereça algumas considerações.

Estes objetivos nos conduziram para a investigação etnográfica, opção metodológica que se caracteriza por buscar o conhecimento a partir da observação direta dos acontecimentos sociais, o que ocorre através de uma relação de comunicação entre o investigador e aqueles que são os protagonistas do contexto cultural em estudo. (Laplantine, 1994). Neste caminho, o trabalho do investigador desenvolve-se num processo de imersão na cultura estudada, na perspectiva de apreendê-la na sua complexidade, muitas vezes não explícita, interpretando-a a partir das significações que os indivíduos atribuem aos seus comportamentos; após este processo, o investigador deve torná-la acessível pela sua apresentação na

entre 14:00 e 15:30 horas. Naquele dia havia em torno 120 participantes (todos homens), distribuídos em várias mesas de jogos e em torno das canchas de bocha (jogando, observando/torcendo e/ou esperando a sua vez de jogar). Nas bocha (jogando, observando/torcendo e/ou esperando a sua vez de jogar). Nas mesas de jogo estavam em torno de 70 pessoas: em 11 destas mesas era praticado o xadrez; em 10 delas praticava-se jogos de cartas; em 5 mesas jogava-se damas; havia, aproximadamente, 50 pessoas, sendo que quase todas estavam em torno da quadra oficial, onde costuma acontecer (e neste caso, ocorria) uma partida entre a SOERAL e um grupo visitante; na quadra ao lado havia apenas 4 homens jogando, ninguém assistindo. Mesmo que nos dias de semana esta atividade seja menor, ela intensifica-se ao final da tarde, quando aproxima-se dos dados referidos acima.

8 Linguagem nativa

Movimento, Porto Alegre, v. 10, n. 2, p.39-55, maio/agosto de 2004 
forma descritiva. Esta é uma característica fundamental dos estudos etnográficos, que, para Geertz (1989), não estão apenas relacionados com a utilização de métodos específicos, mas com um empreendimento intelectual para desenvolver uma descrição densa dos contextos culturais investigados.

\section{O jogo da bocha na SOERAL}

Conforme bibliografia disponível na área e é voz corrente entre os seus praticantes, o jogo da bocha é oriundo da Itália, tendo sido trazido ao Brasil por imigrantes. Inicialmente praticado em São Paulo, difundiu-se por outros estados brasileiros, principalmente naqueles onde houve imigração italiana (Steiger, 1987). Nos dias de hoje esta prática está consolidada, inclusive numa perspectiva institucional, e é praticada em diversas modalidades; ${ }^{10}$ oficialmente, existem três versões mais conhecidas: a Simples, o jogo de Duplas e o de Trios.

Esta última forma (entre trios) é a mais praticada na SOERAL, a qual - assim como as demais - é realizada em uma cancha de 4 por $24 \mathrm{~m}$, delimitada por tábuas de $30 \mathrm{~cm}$ de altura nas laterais e 1,5 m de altura nas cabeceiras; no piso são utilizados materiais variados, podendo ser de terra batida, saibro ou material sintético. ${ }^{11}$ Jogada entre duas equipes que têm 6 bochas ${ }^{12}$ cada uma, uma partida inicia quando o bolim ${ }^{13}$ é arremessado para a zona de jogo, ${ }^{14}$ passando a ser a referência de todos os jogadores, os quais - desde o lado oposto da quadra - têm o objetivo de dele aproximar o maior número das suas bochas, assim como o de afastar as bochas dos seus adversários. Isto é repetido em várias rodadas, quando vão sendo acumulados os pontos de cada equipe, até que uma delas alcance 15 pontos, sagrando-se vencedora.

9 Estando o trabalho ainda não concluído, até o momento foram realizadas 40 idas ao campo (diários de campo) e 3 entrevistas semi-estruturadas.

10 Steiger (1987) apresenta 11 formas diferentes: Simples; Duplas; Trios; Quarteto; Sexteto; Ponto Bol; Jogo Livre; Palmo e Raia; 48 ou Cinquilho; Sueto; Petanca;

11 De acordo com o nível de organização e investimento dos grupos, são utilizados pisos de diferentes qualidades. O piso sintético, utilizado pela SOERAL é considerado o mais qualificado e teve um custo de R $\$ 15.000,00$ (Seu Dutra; Seu Osório).

12 Bola de madeira ou sintética (colorida com cores que identificam as equipes), medindo 12 centímetros de diâmetro e pesando $1,4 \mathrm{Kg}$.

13 Bola de cor branca, com 5 centímetros de diâmetro.

14 Espaço entre duas linhas que estão localizadas a $1 \mathrm{~m}$ de cada cabeceiras e paralelas a estas.

Movimento, Porto Alegre, v. 10, n. 2, p.39-55, maio/agosto de 2004 


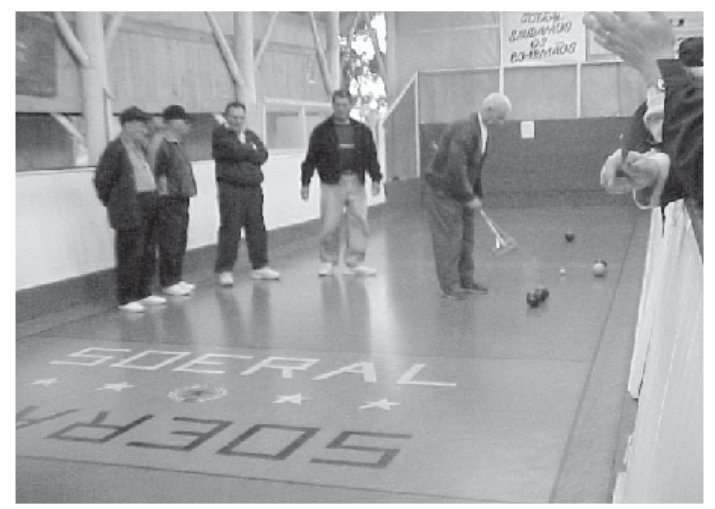

Figura 2. Jogo de bocha na cancha 1.

Tendo estas regras como referência, o jogo acontece numa dinâmica bastante particular, que causa estranhamento a um observador de fora. Isto porque ela envolve uma linguagem própria ${ }^{15}$ que traduz os acontecimentos do jogo, assim como as estratégias técnico-táticas que o praticante precisa dominar e que o espectador necessita compreender. ${ }^{16}$ Também fazem parte deste ambiente as inúmeras brincadeiras, gozações e ironias bem humoradas que são observadas sistematicamente, prevalecendo, assim, um clima onde o não sério parece ser a regra geral.

Este caráter se explicita de forma especial no cotidiano do grupo, quando os jogos são realizados numa perspectiva bastante informal, na medida em que todos os praticantes têm acesso ao jogo, desde que estejam presentes e que incluam os seus nomes num caderno que está disponibilizado ao lado das canchas. Desta forma, todos os freqüentadores têm o direito a jogar, o que é estabelecido por ordem de chegada. Uma vez definidos os seis

15 Algumas expressões: cavalo (tabela na parede lateral); bochada (arremesso aéreo, no qual o jogador visa acertar a bocha do adversário, para afastá-la do bolim); lagarto (tentativa de bochada, mas que - tocando o solo muito antes da bolim); lagarto (tentativa de bochada, mas que - tocando o solo muito antes da aproximando-se da bocha do adversário, com a expectativa de afastá-la do bolim); ponteiro (jogador que faz boas aproximações do bolim); atirador (jogador especializado em fazer bochadas); pangaré (jogador com pouca habilidade técnica); "o jogo não está ligando" (quando a disputa é desigual e não oferece emoção); "jogo ligado" (quando a disputa está equilibrada).

16 Os jogos são sempre muito comentados, tanto pelos jogadores, como pelos espectadores pertencentes ao grupo. Nestes comentários, os nativos conseguem prever o que vai acontecer (na maior parte das vezes sabem a jogada que vai ser realizada, se tem ou não chances de ser bem sucedida), o que não acontece da realizada, se tem ou não chances de ser bem sucedida), o que não acontece da
mesma forma com os espectadores de fora (nós, pesquisadores, na maioria das situações, não tínhamos a mesma capacidade).

Movimento, Porto Alegre, v. 10, n. 2, p.39-55, maio/agosto de 2004 
primeiros, as equipes (dois trios) são divididas consensualmente, de acordo com as características técnicas dos jogadores. Neste sentido, é importante que o jogo "ligue", ou seja, que se estabeleça uma disputa entre equipes equilibradas: "cada um dos atiradores deve ficar num time, se não perde a graça", disse o Italiano, explicitando a preocupação de que o jogo que estava para começar adquirisse um nível ótimo de tensão-excitação, estimulando o aparecimento de uma tensão agradável, conforme nos ensinariam Elias e Dunning (1992). ${ }^{17}$ Ao que parece, nestas situações, os jogadores buscam criar uma configuração, na qual os dois grupos se constituem dois subgrupos interdependentes em tensão, na mesma perspectiva do que Stigger (2001) encontrou, quando estudou grupos de praticantes de esportes no âmbito do lazer e identificou "o valor atribuído aos jogos duros, renhidos, disputados" e apresentou a categoria de companheiro adversário ${ }^{18}$ como uma forma de explicar aspectos da sociabilidade dos grupos. Conforme o autor, mesmo que os indivíduos estejam em oposição no jogo, eles não são adversários que estão numa situação de isolamento e/ou numa forma de conflito negativo: eles estão numa condição de complementareidade, formando um tipo de sociabilidade fundada numa relação de cooperação pela oposição.

Esta idéia se evidencia nas inúmeras vezes que presenciamos situações nas quais os jogadores se congratulavam com os seus oponentes, quando estes realizavam boas jogadas, obtendo, assim, vantagem no jogo; o mesmo juízo pode ser feito quando - mesmo que estejam numa situação de competição - visualizam-se inúmeras brincadeiras entre os participantes de equipes adversárias, assim como as muitas adaptações à regra que são admitidas, no sentido de facilitar a participação de jogadores que têm um menor capital esportivo (Marivoet, 1998, p. 31). ${ }^{19}$ Entre outros exemplos que

17 É este autor que critica a idéia de que a tensão seja pensada apenas numa perspectiva negativa e defende a sua posição questionando: "Se as tensões devem ser avaliadas, pura e simplesmente, como perturbações das quais as devem ser avaliadas, pura e simplesmente, como perturbaçoes das quais as
próprias pessoas se procuram ver livres, porque é que no seu tempo de lazer próprias pessoas se procuram ver livres, porque é que no seu tempo de lazer
elas voltam sempre a procurar uma intensificação das tensões? Em vez de elas voltam sempre a procurar uma intensificação das tensões? Em vez de
condenar nas tensões com algo que prejudica, não se deveria antes explorar as condenar nas tensões com algo que prejudica, não se deveria antes explorar as
necessidades que as pessoas revelam por uma dose de tensão, enfim, como um necessidades que as pessoas revelam por uma dose
ingrediente normal nas suas vidas?" (p. 142-143).

18 A expressão vai ao encontro do pensamento de Michel Bouet (1968), posteriormente revisitado por Guay (1993), acerca do conceito de "com-contra"; Para Bouet (1968: 57), "a tensão em direção ao objetivo e a tensão em direção ao outro são recíprocas e fundadas uma sobre a outra formando uma estrutura outro sao reciprocas e fundadas uma sobre a outra, formando uma estrutura paradoxal que, mal compreendida na sua significação, pode mesmo parecer
absurda".

Movimento, Porto Alegre, v. 10, n. 2, p.39-55, maio/agosto de 2004 
poderiam ser citados sobre este aspecto, presenciamos uma situação na qual um jogador de idade mais avançada dos que os demais, já se mostrando cansado e com dificuldades para realizar a "bochada", foi aconselhado a passar da linha que limita aproximação do seu alvo, como uma forma de facilitar a conclusão da sua jogada.

Com algumas diferenças do que foi referido acima, acontecem os jogos de bocha oficiais, quando os jogadores da SOERAL se confrontam com equipes representativas de outros espaços públicos, no Campeonato Municipal de Praças, realizado pela Prefeitura de Porto Alegre. ${ }^{20}$ Nessas competições evidencia-se um maior preocupação com o resultado das partidas, conduzindo a um aumento do nível de seriedade da atividade. Isso ficou bastante evidente em todas as vezes que visitamos a SOERAL em dia de competição e identificamos um clima diferenciado (mais sério), assim como uma maior concentração de pessoas em volta da cancha em que há jogo oficial, principalmente quando da equipe " $\mathrm{A}{ }^{21}$, comparada à movimentação que ocorre na cancha que está ao lado. ${ }^{22}$

Nestas situações confirma-se o que já havia sido evidenciado em contatos informais, que é um forte sentimento de pertencimento existente naquele local. Se, por um lado - como referido anteriormente - as atividades do grupo estão fortemente centradas no lúdico e na prática desinteressada, por outro, quando jogam à sério afloram-se de forma mais evidente, ${ }^{23}$ os sentimentos que atribuem uma identidade do grupo, diferenciando-o de outros, no contexto da prática da bocha na cidade. Além do orgulho com que

19 Expressão construída a partir do conceito de capital cultural, de Pierre Bourdieu (várias obras): um saber-fazer que possibilita a comparação com os outros participantes.

20 Neste campeonato participam outros grupos, oriundos de diversas regiões da cidade, os quais se deslocam para participar do evento, ora jogando "em casa", ora "fora de casa".

21 No campeonato da Prefeitura cada associação participa com duas equipes, a equipe "A" (de melhor qualidade técnica) e a equipe "B".

22 Onde os jogos são considerados de menor nível técnico (ora jogos informais ora jogos oficiais entre equipes "B").

23 Dizemos mais evidente, pois, em outras situações, também identifica-se o sentimento de pertencimento, mas que chama mais atenção nos momentos de competição. Como exemplo, podemos citar o orgulho que sentiram quando um de seus membros ("Seu" Inácio) foi entrevistado (na sede do grupo) por um de seus membros ("Seu" Inácio) foi entrevistado (na sede do grupo) por um
jornal (Zero Hora), sobre tema da sua área profissional (Economia); outro exemplo jornal (Zero Hora), sobre tema da sua área profissional (Economia); outro exemplo no Museu Antropológico de Porto Alegre.

Movimento, Porto Alegre, v. 10, n. 2, p.39-55, maio/agosto de 2004 
ostentam o uniforme da equipe, ${ }^{24}$ este sentimento está presente nas palavras de vários sócios, quando enfatizam que a SOERAL é bicampeã de bocha de Porto Alegre; é também por sentiremse parte do grupo, que vangloriam-se das suas vitórias, ao afixarem, em local bem visível na sua sede, um faixa dizendo "Valeu SOERAL - bicampeã 2001/2 de bocha". Este sentimento também aparece quando, nos jogos oficiais, o público presente concentrado em torno de uma mesma cancha - configura-se na forma de duas torcidas, cada uma incentivando os participantes dos seus respectivos grupos. ${ }^{25}$

É com este clima que a bocha oficial trás consigo a valorização da performance dos jogadores, situação em que o capital esportivo é bastante reconhecido e na qual o jogo passa a aproximar-se bastante do que é correntemente denominado de esporte. Além do que acontece no momento do jogo, neste contexto, a busca da excelência dos gestos técnicos ocorre, também, em períodos especiais de treinamento, quando os participantes das equipes têm horários exclusivos de uso das canchas, para melhorar o seu rendimento. Este treino é constituído por um aquecimento prolongado, ${ }^{26}$ quando cada um dedica-se à executar o gesto técnico de sua especialidade, ${ }^{27}$ seguido de um jogo. Tanto no treino quanto no jogo oficial identifica-se, também, uma preocupação com a qualidade dos equipamentos: nestes momentos as melhores bochas são as utilizadas, o jogo ocorre naquela que é considerada a melhor das duas canchas, e os jogadores (cada um com o seu) utilizam um pequeno pedaço de pano para secar as mãos e a bocha com que vai jogar. ${ }^{28}$ Seu Dutra descreve este aspecto da sua participação na SOERAL, como o momento em que o jogo especializa-se e torna-se mais sério: "como eu sou um ponteiro, ponteiro tem que ser exigente, para treinar a mão, ainda mais numa cancha sintética que exige muita sensibilidade". É o mesmo participante que enfatiza a valorização do capital esportivo quando afirma que "fazem dois

24 Durante os jogos as equipes utilizam uniformes completos (abrigo e camiseta nas cores preta e amarela) e mesmo aqueles que não fazem mais parte do time (mas já fizeram), costumam utilizá-los.

25 Os torcedores têm uma participação bastante ativa no jogo, incentivando e, inclusive, sugerindo jogadas aos jogadores.

$26 \mathrm{Em}$ momentos que precedem os jogos (mesmo no cotidiano) sempre há um aquecimento (expressão nativa). Nos treinos, este aquecimento é prolongado por, em torno de meia hora.

27 Ponteiro, atirador e intermediário.

28 Alguns destes panos são padronizados e trazem, inclusive, emblemas dos respectivos times.

Movimento, Porto Alegre, v. 10, n. 2, p.39-55, maio/agosto de 2004 
anos que eu jogo no time ' $\mathrm{B}$ ' aqui da SOERAL, torcendo para que amanhã ou depois seja convidado para participar do ' $A$ '; fazer força pra poder participar do ' $A$ ' ".

Tendo em vista a descrição oferecida acima, poder-se-ia identificar, na SOERAL, pelo menos duas formas diferentes da prática do jogo da bocha. Na primeira o jogo ganha um sentido não estritamente ligado à idéia que a competição e as suas características de seriedade e seletividade, se tornando mais relacionado à idéia de divertimento e participação; na segunda o caráter de seriedade vem à tona, passando, a participação, a ser restrita àqueles que apresentam um melhor domínio das habilidades do jogo, ou seja, aqueles que possuem um maior capital esportivo. Nesta ótica, tendo como referência o pensamento de Dunning (1992), poder-se ia dizer que, se numa perspectiva o grupo pratica a bocha a partir de um "ethos amador", ${ }^{29}$ cujo componente principal é a prática do esporte por divertimento, na outra estaria praticando a mesma atividade dentro de um ethos do tipo profissional e cuja orientação está vinculada à seriedade e à busca dos resultados.

Esta interpretação que obtivemos acerca do jogo da bocha está baseada em reflexões desenvolvidas por Dunning (1992), quando ele buscava compreender o significado social do esporte e visualizou uma tendência em direção à luta pelos resultados e para o aumento da seriedade nesta atividade; é neste contexto que ele identificou diferentes significados para esta prática, desde que interpretada a partir dos seus protagonistas e da forma com que estes se apropriam do esporte. Ao encontrar afinidades entre os significados com que o jogo da bocha é desenvolvido na SOERAL e as referidas análises acerca do esporte, somos conduzidos a perguntar: onde se insere o jogo da bocha, no contexto do jogo ou no contexto do esporte? Este questionamento se torna mais provocativo, quando identificamos - na linguagem corrente - situações em que estas palavras se confundem: mesmo que, em várias situações, os jogadores de bocha inserem a sua atividade no contexto do esporte, ${ }^{31}$ esta prática é

29 Atividades que têm um fim em si mesmas e cujo acento tônico estaria no prazer e constituiriam "formas de participacão nos esportes 'dirigidos para si próprio' ou 'egocêntricos" (Dunning (1992: 312).

30 "Formas de participação 'dirigidas para os outros' " (Dunning 1992: 317), tanto adversários, como espectadores. Contrariamente às anteriores, estas práticas estão vinculadas ao que está em jogo, quer sejam interesses materiais, quer sejam satisfações relacionadas com a identidade e com o prestígio.

31 Não são poucas as declarações de seus praticantes neste sentido.

Movimento, Porto Alegre, v. 10, n. 2, p.39-55, maio/agosto de 2004 
socialmente considerada como um jogo; e apesar de, em inúmeras situações, as pessoas fazerem afirmações no sentido de que vão assistir a um jogo de futebol, elas não têm dúvidas de que estão se referindo a algo que socialmente é aceito como um esporte. Por outro lado, também no campo acadêmico - e mesmo sem que haja uma intenção específica no sentido de que sejam traçadas fronteiras entre elas - são identificadas circunstâncias em que estas noções ${ }^{32}$ são referidas por oposição, uma à outra.

Neste universo conceitual pouco esclarecido, a pergunta acima acaba por colocar em discussão alguns aspectos relativos às diferenças entre o jogo e o esporte, no que se refere à forma como estas atividades vêem sendo tratadas na literatura da área. Não são poucos os autores que identificam estes elementos da cultura como práticas que trazem consigo características bastante diferenciadas, senão opostas: muitas vezes, quando a intenção é caracterizar o esporte, isto é feito pela oposição ao jogo; em outros momentos ocorre o caminho inverso e a tentativa de delimitar a idéia de jogo é feita pela confrontação com o esporte.

Um exemplo disto é a posição de Huizinga (1980), quando, na sua clássica obra em que buscava compreender o jogo como um elemento da cultura, desenvolve suas idéias no sentido de que o esporte moderno corrompeu as características lúdicas do jogo, transformação que - segundo ele - estaria ligada ao fato da sociedade contemporânea haver perdido muitos dos seus elementos lúdicos que existiam anteriormente, ou seja, o seu caráter de divertimento ocasional que teria sido deslocado no sentido da seriedade. Huizinga defende que - apesar de, à primeira vista, parecer que o esporte estaria vinculado à esfera lúdica -, isto efetivamente não acontece, pois, comparado com os jogos anteriores ligados ao divertimento ocasional, o esporte sofre uma deslocação no sentido da seriedade. Isto estaria explícito no fato de que o “espírito profissional não é mais o espírito lúdico, pois lhe falta a espontaneidade, a despreocupação" (p. 219), o que "afeta também os amadores, que começam a sofrer de um complexo de inferioridade" (p. 219-220). Em que pese o fato desta obra ser uma publicação datada há muito tempo, ela se constitui um clássico muitas vezes referido no contexto da Sociologia do Esporte e as suas idéias, mesmo que não explicitadas, acabam por se assemelhar a outras, com relativa atualidade.

32 Utilizamos esta palavra, na busca de relativisar e evitar posições rígidas como conceitos ou mesmo definições.

Movimento, Porto Alegre, v. 10, n. 2, p.39-55, maio/agosto de 2004 
É o caso de Guay (1993), que, ao referir-se à cultura esportiva coloca em dúvida a existência do esporte desinteressado, ou seja, sem que não haja nada em jogo e no qual o divertimento seja uma característica central. Neste sentido, o autor considera que o divertimento é um dos componentes do esporte, mas que este aspecto não pode sobrepor-se aos demais, dentre os quais a competição e o resultado, o que faria com que uma atividade assim desenvolvida deixasse de ser esporte, para ser uma "paródia do esporte" (p. 49). É assim que ele interpreta as atividades esportivas vinculadas ao esporte para todos, nas quais, sendo "acessível a todos e a todas, sem árbitro, sem vencedores nem vencidos, mas unicamente por prazer de jogar (...) os jogadores não praticam mais o esporte, mas fazem a simulação; eles não estão mais no universo esportivo" (p. 49).

Este pensamento está relacionado com o conceito de esporte por ele desenvolvido, no qual está inserido o componente "o que está em jogo" (p. 52-57), elemento não apenas relacionado com os interesses materiais, mas ampliado para aspectos como o prestígio pessoal e de grupo, os quais, segundo ele, também fazem parte do que dá sentido à cultura desportiva. Mesmo que Guay (1993) não esteja - explicitamente - contrapondo a noção de esporte à de jogo, ele se aproxima das posições de Huizinga, quando - ao tentar caracterizar o esporte e mesmo que utilize outras expressões - coloca o lúdico, o divertimento, a espontaneidadee a atividade desinteressada em oposição à competição, ao resultado, à seriedadee aos interesses em jogo. Além de considerarmos que isto está evidente nas palavras destes autores, acreditamos que estas oposições fazem parte do linguajar corrente neste campo de investigação, algo que não parece necessário ser documentado.

Por outro lado, é interessante identificar que o mesmo Huizinga - que é crítico relativamente à seriedade do esporte moderno e defensor do espírito lúdico e da gratuidade dos jogos - é referido por autores que identificam a forma gratuita e desinteressada presente em diversas atividades esportivas estudadas. De fato, é utilizando os conceitos de Huizinga, que Segalen (1994) amplia a noção de esporte e encontra a mesma gratuidade por ele invocada acerca do jogo, no que representam as competições de corridas de rua, ${ }^{33}$ para muitos dos corredores comuns. Nestas situações, diz a autora, "estamos mais perto do jogo do que do esporte, mais perto da recreação do que da competição" (p. 115).

33 Nos seus exemplos, a autora refere-se, inclusive, a competições de caráter oficial e mesmo bastante conhecidas: maratona de Nova lorque, de Estocolmo; de Berlim, e outras.

Movimento, Porto Alegre, v. 10, n. 2, p.39-55, maio/agosto de 2004 
Resultados semelhantes aos de Segalen foram os encontrados por Stigger (2001), quando, ao estudar grupos de praticantes de esportes no lazer, identificou atividades reconhecidas socialmente como esportes (futebol e voleibol) sendo praticadas a partir de uma lógica que as aproximava das características que são atribuídas aos jogos, conforme o que vem sendo referido. Concordando com Padiglione (1995), o autor interpretou estas atividades como uma diversidade cultural no contexto dos esportes e defendeu a idéia de que é difícil tentar compreender esta prática social a partir de limites rígidos e sem que sejam considerados os significados que elas têm para os seus protagonistas.

Esta linha de argumentação pode ser considerada para a compreensão das atividades desenvolvidas pelos integrantes da SOERAL, estes que, apesar de estarem inseridos num contexto socialmente identificado como o mundo do jogo, ${ }^{34}$ vivenciam estas práticas, não raras vezes, de forma bastante séria e bastante próxima do universo esportivo.

\section{Considerações finais}

Neste trabalho, procuramos, a partir da etnografia, compreender aspectos do modo com que os sócios da Sociedade Esportiva Recanto da Alegria/SOERAL vivenciam seu tempo livre, realizando diversos tipos de atividades, as quais poderiam ser inseridas no campo das práticas corporais lúdico-esportivas. Além da compreensão daquele universo cultural particular, o contato com os participantes do grupo nos proporcionou algumas reflexões acerca de discussões presentes no campo de estudo da Sociologia do Esporte.

Centrando a atenção na forma com que os protagonistas daquele contexto praticam o jogo da bocha, acabamos por perguntar se esta atividade se insere no contexto do jogo ou do esporte. Sem, efetivamente, tentar responder a esta pergunta, fizemos uso daquela realidade empírica para nos aproximarmos da temática, no sentido de problematizá-la e provocar a discussão, estabelecendo um diálogo com alguns autores. Esta aproximação nos mostrou as dificuldades que encontram aqueles que analisam o esporte e o jogo, enquanto práticas de lazer, numa perspectiva dicotômica e distanciada dos contextos empíricos onde elas se realizam. Se por

34 Sobre isto, ver Loret (1996)

Movimento, Porto Alegre, v. 10, n. 2, p.39-55, maio/agosto de 2004 
um lado, encontramos a bocha sendo praticada (e sendo possível de ser interpretada) a partir de categorias que são utilizadas, por muitos autores, para a compreensão do jogo (o lúdico, o divertimento, a espontaneidade e a atividade desinteressada), por outro, a mesma atividade foi possível de ser compreendida com base em categorias correntemente vinculadas ao esporte (a competição, o resultado, a seriedade e os interesses em jogo). Desta forma, poderíamos dizer, assim como Bromberger (1998) se refere ao futebol, que, dependendo do significado atribuído pelos seus praticantes, uma atividade de lazer, como o jogo da bocha, pode vir a ser uma bagatela bastante séria. Isto tanto no que se refere à importância que estas atividades têm para a vida dos seus praticantes, ${ }^{35}$ como no que tange à discussão desenvolvida acima, acerca das relações entre jogo e esporte.

Com base nestes resultados, consideramos que o olhar antropológico e a etnografia podem ser uma alternativa de compreensão de universos particulares enquanto moduladores de símbolos e estratégias próprias. Universos estes que, de outra forma poderiam estar confinados em uma perspectiva universal, condicionada aos modelos relacionados aos processos macro sociais, distanciados dos contextos particulares onde eles se materializam.

The practice of "boccie" in the SOERAL: between game and sport

Abstract: In this work, we seek to, from the ethnography, understand aspects of the way that the members of the Sociedade Esportiva Recanto da Alegria/SOERAL live their free time. Centering the attention in practice of the boccie game that takes place there, we ask if this activity is inserted in the context of game or sport. Without, effectively, trying to answer this question, we made use of that empiric duality to problematize it and excite a discussion about the relations between game and sport. This approximation showed us the difficulties that those who analyze sport and game in a dichotomist way find, far from the empiric contexts where they are.

Key words: LeIsure, Game, Sport, Ethnography.

35 Nos referimos, aqui, à importância atribuída pelos freqüentadores da SOERAL à sua participação naquele grupo de convivência que, para muitos deles, é um espaço de sociabilidade fundamental para as suas vidas. Mas isto é outro assunto, que será tratado em outro trabalho

Movimento, Porto Alegre, v. 10, n. 2, p.39-55, maio/agosto de 2004 


\section{La práctica de la "bocha" en la SOERAL: entre el juego y el deporte \\ Resumen: En este trabajo, procuramos, a partir de la etnografia, comprender aspectos del modo com que los socios de la "Sociedade Esportiva Recanto da Alegria/SOREAL (Sociedad Deportiva Recanto de la Alegria) vivencian su tiempo libre. Centrando la atención en la práctica del juego de la bocha que allá sucede, preguntamos si está actividad se insiere en el contexto del juego o del deporte. Sin, efectivamente, intentar responder a esta pregunta, hicimos uso de aquella realidad empírica para problematizarla y provocar la discución acerca de las relaciones entre el juego y el deporte. Esta aproximación nos mostró las dificultades que encuentran los que analizan el deporte y el juego en una perspectiva dicotómica, distanciada de los contextos empíricos donde ellas se realizan. \\ Palaibras-ciave: Ocio, Juego, Deporte, Etrograriाa.}

\section{Referências:}

BOUET, Michel. Signification du Sport. Paris: Éditions Universitaires, 1968. BROMBERGER, Christian. Football, la bagatelle la plus sérieuse du monde. França: Bayard Éditions, 1998.

DUNNING, Eric. A dinâmica do desporto moderno: notas sobre a luta pelos resultados e o significado social do desporto. In: ELIAS, Norbert e DUNNING, Eric. A Busca da Excitação. Lisboa: Difel, 1992, 299-235.

ELIAS, Norbert e DUNNING, Eric. A Busca da Excitação. Lisboa: Difel, 1992.

FORTUNA, Carlos. Sociologia e Práticas de Lazer. In: Revista Crítica de Ciências Sociais. Coimbra: Centro de Estudos Sociais, 1995, 43, 5-10.

GEERTZ, Clifford. A interpretação das culturas. Rio de Janeiro: Editora Guanabara Koogan, 1989.

GUAY, Donald. La culture sportive. Paris: Presse Universitaires de France, 1993. HUIZINGA, Johan. Homo Ludens. São Paulo: Perspectiva, 1980.

LAPLANTINE, François. Aprender Antropologia. $8^{\mathrm{a}}$ ed. São Paulo: Brasiliense, 1994.

LORET, Alain. Génération Glisse: dans l'eau, l'air, la neige.... la révolution du sport des "années fun". Paris: Autrement, 1996.

MAGNANI, José Guilherme C. Festa no Pedaço - Cultura Popular e Lazer na Cidade. São Paulo: Brasiliense, 1984.

MARIVOET, Salomé. Aspectos Sociológicos do Desporto. Lisboa: Livros Horizonte, 1998.

Movimento, Porto Alegre, v. 10, n. 2, p.39-55, maio/agosto de 2004 
PADIGLIONE, Vicenzo. Diversidad y pluralidad en el escenário deportivo. In: Apunts: Educación Física y Deportes. Barcelona: INEF de Catalunya, 1995, 41, 30 35.

SEGALEN, Martine. Les Enfants d'Achille et de Nike - une ethnologie de la course à pied ordinaire. Paris: Éditions Métailié, 1994.

STEIGER, Roger Nelson. O Emocionante e Espetacular Esporte da Bocha. Porto Alegre: Sulina, 1987

STIGGER, Marco Paulo. Esporte, lazer e estilos de vida: Um estudo etnográfico. Campinas, SP: Autores Associados, 2002.

Marco Paulo Stigger Escola de Educação Física

Rua Felizardo, 750

Jardim Botânico

Porto Alegre

90690-200

stigger@adufrgs.ufrgs.br

Raquel da Silveira Rua Barão do Amazonas, 1580/402

$$
\text { Partenon }
$$

CEP: 90670-002

Porto Alegre - RS

raqkarate@hotmail.com

Movimento, Porto Alegre, v. 10, n. 2, p.39-55, maio/agosto de 2004 